\title{
Determining Discounts For Perishable Inventory
}

Tom Bramorski, (Email: bramorst@uww.edu), University of Wisconsin, Whitewater

\begin{abstract}
In this paper, we develop a model to help manage prices of perishable products in a grocery store. We consider inventory on hand and proximity to expiration date as key decision variables. We also discuss the strategic importance of minimizing inventory that must be disposed of at a cost after the product expires. We also develop simple applied rules and highlight the benefits of using a dynamic pricing model to companies selling perishable products.
\end{abstract}

\section{THE PROBLEM BACKGROUND}

¿

$\mathrm{n}$ recent years, multiple retail and wholesale industries have come under an increasing pressure from global competitors due to diminished trade barriers and ease of market penetration. Globalization has produced a set of price, quality and time-related competitive challenges to businesses forcing them to reduce production cost and improve efficiency. The need to reduce production cost has led, amongst other things, to the elimination of thousands of well-paying jobs in developed countries and lowering the after-tax income of many classes of consumers. Consequently, the ranks of price-sensitive consumers postponing their purchasing decisions in a perpetual quest for a bargain have increased. One way to improve operation efficiency to lower costs is through better management of inventories and improving inventory turns. The shelf life of products that do not achieve their sales and profit targets has become increasingly shorter. As a result, the problem of effectively managing inventories of hundreds of SKUs in retail stores and wholesale outlets offering perishable items has become even more important. Further, quality has become one of the most important customer decision factors in the selection among competing products and services. Thus, it would be interesting to study the impacts of the product quality and the quality-related costs on the optimal pricing and ordering policies. Clearly, proximity to expiration date is one measure of perishable product quality.

\section{THE RESEARCH DESIGN}

The data on consumers' attitudes toward purchasing dairy products with varying proximity to expiration data was collected through a questionnaire administered over a period of two years to undergraduate and graduate students enrolled at the University of Wisconsin-Whitewater. The sample size was 147 of which $n=129$ were complete and valid responses. Respondents who indicated they purchased and consumed milk were asked to provide demographic and economic information about themselves and their families and to indicate whether they would purchase milk that had been on the store shelves for some time. 98 percent of the respondents indicated that they consistently check expiration date on milk and other perishable products and purchase them using a LIFO scheme despite the fact that nutritional and other product characteristics remain stable over the entire shelve live period.

\begin{tabular}{|c|c|c|c|}
\hline Check Discount? & Count & \% of Col & \% of Tbl \\
\hline 0 & 3 & 2.33 & 2.33 \\
\hline 1 & 126 & 97.67 & 97.67 \\
\hline All & 129 & 100.00 & 100.00 \\
\hline
\end{tabular}

Table 1: The percentage of consumers purchasing milk who check expiration date. 
When offered a progressive price discount of increasing magnitude, an increasing number of consumers indicated that they would consider it. Based on the responses in Table 2, we formulated and tested several research hypotheses.

\begin{tabular}{|c|c|c|c|}
\hline & \multicolumn{3}{|c|}{ Days Remaining to Expiration Date } \\
\hline Discount & $\mathbf{1 0 - 1 4}(\mathbf{m a x})$ & $\mathbf{5 - 9}$ & $\mathbf{0 - 4}$ \\
\hline $0 \%$ & 98 & 2 & 0 \\
\hline $5 \%$ & 90 & 7 & 3 \\
\hline $10 \%$ & 72 & 18 & 10 \\
\hline $15 \%$ & 61 & 27 & 12 \\
\hline $20 \%$ & 52 & 31 & 17 \\
\hline $25 \%$ & 45 & 36 & 19 \\
\hline
\end{tabular}

Table 2: The percentage of consumers purchasing milk depending on proximity to expiration date and price discount offered.

Figure 1 summarizes the results in Table 2 categorized by days remaining to expiration date. The plot demonstrates that as the price discount increases respondents are more willing to purchase milk closer to expiration date.

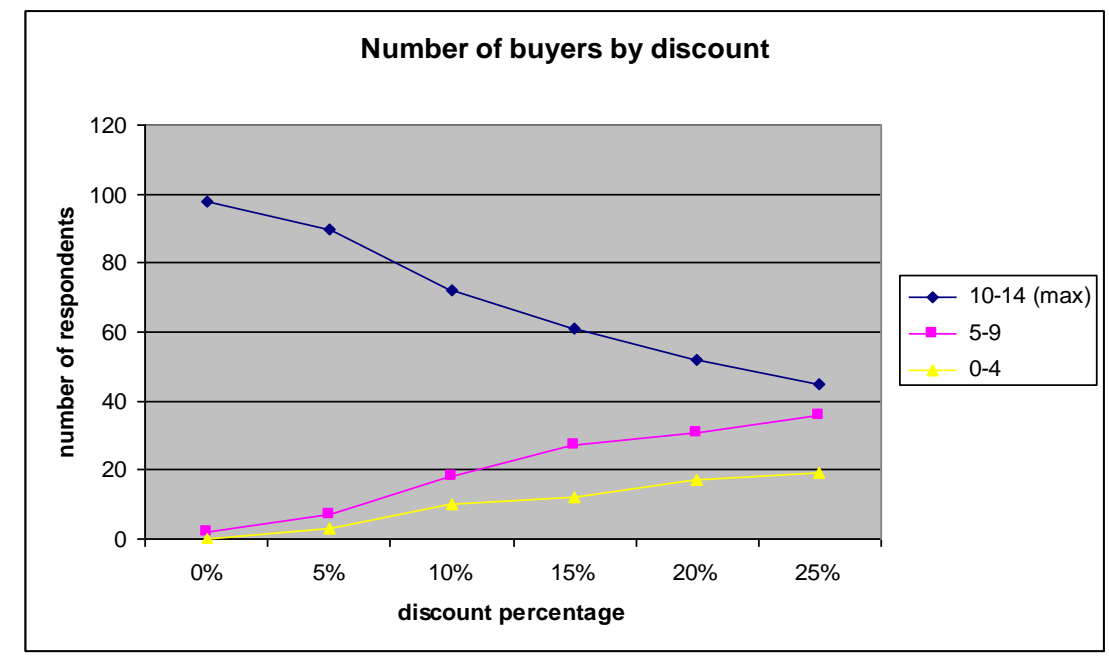

Descriptive Statistics for the three categories of milk based on proximity to expiration date: 10-14, 5-9, 0-4

\begin{tabular}{crrrr} 
Variable & Mean & Median & StDev & SE Mean \\
\hline $10-14$ & 89.8 & 86.0 & 27.0 & 11.0 \\
$5-9$ & 26.00 & 29.00 & 17.34 & 7.08 \\
$0-4$ & 13.17 & 14.00 & 9.79 & 4.00 \\
\hline
\end{tabular}

Figure 1: The number of respondents purchasing milk depending on proximity to expiration date and price discount offered. 


\section{THE RESEARCH HYPOTHESES}

Based on the collected data and the descriptive statistics presented above we investigate the following research hypotheses:

1. $\mathbf{H}_{0}$ : The proportions of consumers who check and do not check product expiration date in purchasing milk are equal $\left(\pi_{0}=\pi_{1}\right)$,

$\mathbf{H}_{1}$ : Otherwise.

This hypothesis suggests that consumers are quality conscious. They view quality of a perishable product, such as milk, as related to the expiration date. Even though Government (FDA) and independent food testing organizations suggest otherwise, consumers view quality of food products close to expiration date as lower compared to that of recent deliveries. All other things being equal, rational consumers will check the expiration date on products, such as milk, and purchase the product that is the freshest. This last-in-first-out (LIFO) behavior is justifiable from the point of view of the consumer but is undesirable from the point of view of the vendor. It leads to an accelerated depletion of the freshest items leaving excessive inventory of older items in the store forcing vendors to pay to dispose of food products whose expiration date had passed. From the point of view of the vendor, it is desirable to change consumer behavior to first-in-first-out (FIFO) in order to minimize or eliminate any quantity of unsold and obsolete product.

Test of $\mathrm{p}=0.5$ vs $\mathrm{p}$ not $=0.5$

Success $=1$

$\begin{array}{lrrlrr} & & & & \text { Exact } \\ \text { Variable } & \mathrm{X} & \mathrm{N} & \text { Sample } \mathrm{p} & 95.0 \% \text { CI } & \text { P-Value } \\ \text { check } & 126 & 129 & 0.976744 & (0.933541,0.995178) & 0.000\end{array}$

The null hypothesis is rejected ( $\mathrm{p}$-value $=0$ ). Consumers check milk expiration date.

2. $\mathbf{H}_{\mathbf{0}}$ : Consumers purchasing milk will not consider proximity to expiration date if offered a price discount,

$\mathbf{H}_{1}$ : Otherwise.

This hypothesis suggests that consumers are price-sensitive and are willing to trade product freshness for money when a price discount is offered for products close to expiration date. As noted in the discussion of hypothesis \#1 above, rational consumers will typically check the expiration date of products, such as milk, and purchase the product that is the freshest. It is reasonable to expect that, when offered a price discount, consumers will select perishable products close to expiration date under certain conditions. These conditions are examined further in this research.

Chi-Sq $=169.002$, P-Value $=0.000$

The null hypothesis is rejected ( $\mathrm{p}$-value $=0$ ). Consumers will consider purchasing milk closer to expiration date when offered a discount.

3. $\quad \mathbf{H}_{\mathbf{0}}$ : Income is not a significant variable in determining whether consumers consider a price discount in purchasing milk,

$\mathbf{H}_{1}$ : Otherwise. 
This hypothesis suggests that consumers that are more affluent are less price-sensitive and are less willing to trade product freshness for money when a price discount is offered for products close to expiration date. This behavior is justifiable from an economic perspective, since for affluent customers the marginal value of purchasing the freshest milk available exceeds the marginal value of money saved because of taking a discount.

Chi-Sq $=112.622$, P-Value $=0.000$

The null hypothesis is rejected ( $\mathrm{p}$-value $=0$ ). Income is a statistically significant variable in determining whether consumers will purchase milk closer to expiration date when offered a discount.

4. $\quad \mathbf{H}_{\mathbf{0}}$ : Consumers with fewer number of children living in a household are less willing to consider a price discount in purchasing dairy products,

$\mathbf{H}_{1}$ : Otherwise.

This hypothesis suggests that households with fewer children are less willing to trade product freshness for money when a price discount is offered for products close to expiration date. This behavior is justifiable from an economic perspective, since demand for milk in households with more children is higher. Therefore, a package of milk close to expiration date is more likely to be depleted before the product expires.

Chi-Sq $=151.413$, P-Value $=0.000$

The null hypothesis is rejected ( $\mathrm{p}$-value $=0$ ). Income is a statistically significant variable in determining whether consumers will purchase milk closer to expiration date when offered a discount.

Suppose that the shelf life of milk from the time of delivery to the store to expiration date is $\mathrm{m}=14$ days. The quantity not sold during the m-day window and remaining in the store must be disposed of at the cost of $\mathrm{S}$ dollars per unit. The management and disposal of unsold and obsolete inventory is the responsibility of a store management. In order to minimize or eliminate these instances the store management can offer in-store specials and discount milk that is close to the expiration date to stimulate demand.

The store delivery timing and milk order quantity are fixed for each store and are determined centrally using a push-type distribution system. Major milk distributors, such as Dean Foods, perform forecasting centrally for all stores based on the analysis of past demand. Since milk is typically delivered to the store twice weekly, it follows that at any point of time items from a maximum of 4 most recent deliveries can be present on the store shelves at any point of time. At present, the central distribution system allocates product generously to the stores in order to avoid stockouts. As a result, substantial quantities of unsold milk must be disposed of after the expiration date had passed.

\section{THE RESEARCH OBJECTIVES}

Currently grocery stores offer periodic price discounts that apply to certain categories of products and remain in effect for a fixed time period (usually a few days) or until the entire inventory has been sold out. This is inefficient since the quantities on the shelf would often be sold out at the regular price based on the analysis of past demand patterns. In this paper, we develop a stochastic model that can be used by a store manager to help determine in real time the magnitude and timing of a price discount for milk. The discount decision would be taken on a daily basis before the store opens. It takes into account the quantity of inventory on-hand at the beginning of the day and proximity to the expiration date. Increasing the frequency of decisions regarding the discount would maximize profit over the product lifetime while eliminating the disposal cost. 


\section{THE LITERATURE SURVEY}

In this research, we focus on milk as a representative product in the perishable items category. We give special attention to milk but consumer attitudes and behavior toward other food products are similar. Dairy and other product are typically classified as Days Fresh (DF) since their shelf life is measured in days. We quote after [1] that "These items may have products with different ages on the shelves. Moreover, since their shelf life is small (approximately one week), the danger for waste is clearly present." Consumers' preference for LIFO inventory management policy and store management's preference for FIFO are rational and intuitive. In previous research, these preferences have been treated as given and fixed while in reality they are dynamic.

A general cost structure of deterministic demand models studied in the literature quantifies the following cost components:

\footnotetext{
- $\quad$ The ordering cost

- The setup cost

- $\quad$ The obsolescence cost

- $\quad$ The holding cost, and

- The shortage cost.
}

The focus of the research to date has been determining optimal ordering policies (i.e. order quantity and timing for each SKU) for fixed life perishable inventory. Factors such as product freshness, taste, calorific content, etc. have been addressed by developing a weighted utility measure.

The literature on the subject focuses either on perishability or on demand substitution. On paper combines the two perspectives [2]. A review of the literature on inventory systems with perishable items is provided in [3]. [4], and [5]. These references focus on determining optimal reorder policies for perishable items taking into account the total inventory position. Perishability makes the replenishment model more difficult to formulate and solve since the reorder quantity depends on detailed information about the number of items in stock per age. Adding the substitution aspect to the equation makes the problem even worse to analyze. Reference [6] presents a pricing model for perishable items, in which a seller must determine the price for several units of a perishable or seasonal product to be sold for a limited period to maximize expected profit. In this model, on-hand inventory is considered as a decision variable. No references that determine optimal pricing policy for perishable items and simultaneously consider proximity to expiration date and on-hand inventory.

The model formulations utilize dynamic programming and stochastic dynamic programming approaches under various demand distributions and perishability patterns. This research shows that the optimal policy will require the decision maker to replenish inventory so that items will never become obsolete. A common conclusion following [6] is that an optimal policy orders only when on-hand inventory position of an SKU is zero. The policy allows no orders unless inventories from previous orders have been depleted through sale or perishing.

\section{THE MODEL}

In this model, we consider the problem of inventory management for $\mathrm{i}$ items as a separable stochastic programming problem. A decision must be made at time $\mathrm{t}$ regarding every item. In this research, the price discounting process is modeled as a two-action Markov decision model. The following notation is used in the formulation:

$\mathrm{t}=0,2, \ldots \mathrm{m}$. The number of days the product spent on the shelf.

$\mathrm{I}_{\mathrm{t}}=$ Quantity on-hand of an item at time $\mathrm{t}$.

$\mathrm{c}=$ Item cost per unit.

$\mathrm{p}_{\mathrm{t}}=$ Item price per unit at time $\mathrm{t}$.

$\mathrm{s}(\mathrm{j})=$ Salvage cost per unit incurred at stage $\mathrm{j}$. 
$\mathrm{R}_{\mathrm{t}}=$ Expected item requirements at time $\mathrm{t}$.

Milk is a normal good since for $d_{t} \geq 0, R_{t}\left(p_{t}-d_{t}\right) \geq R_{t}\left(p_{t}\right)$

$\Omega_{\mathrm{t}}=$ Set of delivery days for products on-hand at time t.

$\mathrm{D}_{\mathrm{t}}=$ Expected demand at time $\mathrm{t}$ for all items in $\Omega_{\mathrm{t}}$.

$\mathrm{d}_{\mathrm{t}}=$ Price discount per unit at time $\mathrm{t}$.

$\mathrm{i}=\left(\mathrm{I}_{\mathrm{t}}, \mathrm{m}-\mathrm{t}\right)$. This is a state vector.

$\mathrm{h}=$ Holding cost rate per dollar held in inventory per day [ $\$ / /$ day] .

$\mathrm{K}=$ Setup cost. It includes reprogramming of checkout counters, posting markdowns, red tags, etc.

$\mathrm{a}=1$, if a price discount decision is made at time $\mathrm{t}$. $\mathrm{a}=0$, otherwise.

$\mathrm{C}(\mathrm{i}, \mathrm{a})=$ Total cost incurred when action $\mathrm{a}$ is taken in state $\mathrm{i}$.

$\mathrm{P}(\mathrm{i}, \mathrm{a})=$ Total profit made when action a is taken in state $\mathrm{i}$.

$\mathrm{p}_{\mathrm{ij}}(\mathrm{a})=$ Probability that a system that is in state $\mathrm{i}$ at the beginning of a day (period) will be in state $\mathrm{j}$ at the beginning of the following day (period) when action a is taken at time $t$.

$\mathrm{V}(\mathrm{i}, \mathrm{m})=\mathrm{m}$-stage undiscounted cost when the initial state of the process is $\mathrm{i}$. as follows:

Since the inventory on-hand will change by the demand at time t, the transition probabilities are determined

$\mathrm{p}_{\mathrm{ij}}(\mathrm{a}=0)=\operatorname{Prob}\left[\mathrm{R}_{\mathrm{t}}\left(\mathrm{p}_{\mathrm{t}}\right)\right]$

$\mathrm{p}_{\mathrm{ij}}(\mathrm{a}=1)=\operatorname{Prob}\left[\mathrm{R}_{\mathrm{t}}\left(\mathrm{p}_{\mathrm{t}}-\mathrm{d}_{\mathrm{t}}\right)\right]$

The one-stage costs are as follows:

$\mathrm{C}(\mathrm{i}, \mathrm{a})=\mathrm{hc}\left[\mathrm{I}_{\mathrm{t}}-\mathrm{R}_{\mathrm{t}}\left(\mathrm{p}_{\mathrm{t}}\right)\right]$, if $\mathrm{a}=0$, and

$C(i, a)=K+h c\left[I_{t}-R_{t}\left(p_{t}-d_{t}\right)\right], \quad$ if $a=1$.

where:

$\mathrm{K} \geq 0$

$R_{t}\left(p_{t}-d_{t}\right) \geq R_{t}\left(p_{t}\right)$ for $d_{t} \geq 0$.

The one-stage profit function is given by:

$P(i, a)=\left(p_{t}-c\right) R_{t}\left(p_{t}\right)-h c\left[I_{t}-R_{t}\left(p_{t}\right)\right], \quad$ if $a=0$, and

$P(i, a)=\left(p_{t}-d_{t}-c\right) R_{t}\left(p_{t}-d_{t}\right)-h c\left[I_{t}-R_{t}\left(p_{t}-d_{t}\right)\right]-K, \quad$ if $a=1$.

Finally, the total profit can be found from:

$$
\begin{aligned}
& \mathrm{V}(\mathrm{i}, \mathrm{m})=\max [\mathrm{f}(\mathrm{a}, \mathrm{m})]=\max \left\{\left(\mathrm{p}_{\mathrm{t}}-\mathrm{c}\right) \mathrm{R}_{\mathrm{t}}\left(\mathrm{p}_{\mathrm{t}}\right)-\mathrm{hc}\left[\mathrm{I}_{\mathrm{t}}-\mathrm{R}_{\mathrm{t}}\left(\mathrm{p}_{\mathrm{t}}\right)\right]+\sum_{\mathrm{j}} \mathrm{p}_{\mathrm{ij}}(\mathrm{a}=0) \mathrm{V}(\mathrm{i}, \mathrm{m}-1)\right. \text {; } \\
& a=0, \quad a=0,1 \quad j=0 \\
& \left(p_{t}-d_{t}-c\right) R_{t}\left(p_{t}-d_{t}\right)-h c\left[I_{t}-R_{t}\left(p_{t}-d_{t}\right)\right]+\Sigma p_{i j}(a=1) V(i, m-1) ; \\
& \mathrm{j}=0
\end{aligned}
$$

By assumption, $V(j, 0)=-s(j)$. That is, when the expiration date is reached a fixed charge of $s(j)$ is incurred to remove the remaining items from the store shelves. This charge is state-dependent.

\section{PRELIMINARY RESULTS}

Consider a perishable product (milk) that sells for $\$ 3.00$ per unit and has a shelf life of 14 days. After expiration date, it must be disposed of at the cost $\mathrm{s}=10$ percent of the purchase price ( $\$ .30 / \mathrm{unit})$. Hence, it is optimal to offer customers a price discount of $\$ 3.00$ (or 100 percent of the purchase price) if the product will expire and will have to be removed from the store shelves at the end of a business day. 
Preliminary computational results using the model confirm the intuitive result that the magnitude of the price discount correlates positively with proximity to expiration date. The fewer days remain to expiration date the larger the applied discount should be $(\mathrm{r}=.95)$. A price discount also correlates positively with net on-hand inventory (i.e. the difference between on-hand quantity and expected demand to expiration date). The higher the inventory level the larger the applied discount $(\mathrm{r}=.91)$. The resulting relationship for proximity to expiration date ranging from 0 to 14 days and selected net inventory on-hand levels ranging from 0 to 300 units are shown in Figure 2.

\section{Discount by Proximity to Expiration by Inventory Level}

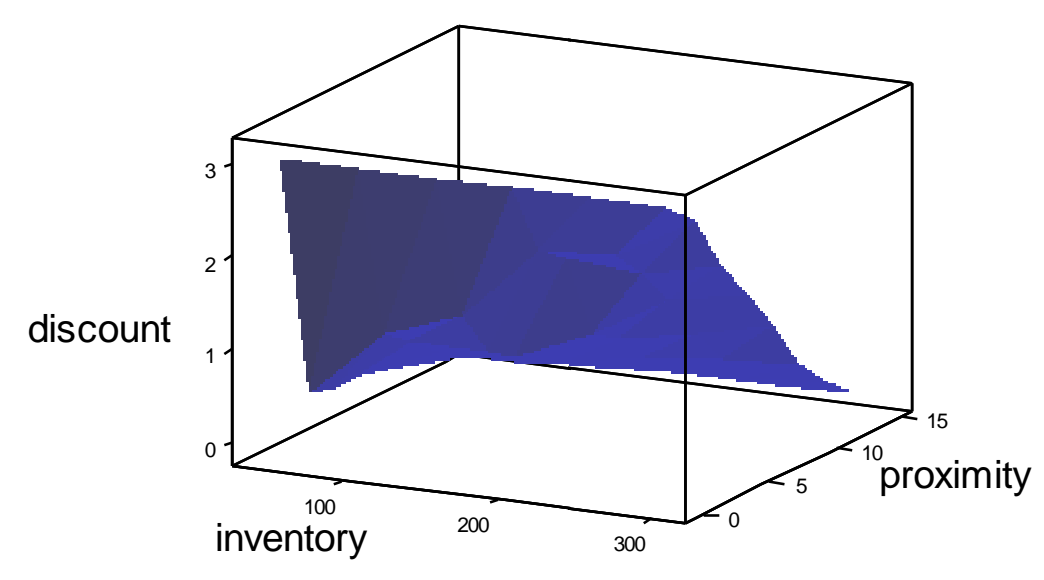

Purchase price $=\$ 3.00 /$ unit

Shelve life time $=14$

Figure 2: The relationship of a discount, proximity to expiration date and inventory on-hand.

\section{THE DECISION RULES}

For practical purposes, we propose a set of simple decision rules based on the model presented above. These rules take into account current inventory position of the product and proximity to expiration date. Intuitively, the larger the amount of inventory the larger the price discount. Similarly, the closer to product expiration date the larger the price discount. These rules can be used by a store manager can use daily in order to set the product price for that day.

Suppose that at the beginning of day $t$, on-hand inventory is $I_{t} \leq I_{t}{ }^{*}$. Then, no price discount should apply. Otherwise, a discount $d_{t}$ should be applied to all units of the product that remain on the store shelves.

The quantity $\mathrm{I}_{\mathrm{t}}^{*}$ is defined as:

$\mathrm{I}_{\mathrm{t}}^{*}=\min \left[\mathrm{I}_{\mathrm{t}} ; \mathrm{f}(\mathrm{a}=0, \mathrm{~m}) \leq \mathrm{f}(\mathrm{a}=1, \mathrm{~m})\right]$

$\mathrm{j}=0$

After all parameters have been estimated the store manager can offer a discount $d_{t}$ on day $t$. 


\section{CONCLUSIONS}

In this paper, we presented a model for determining the inventory policy regarding managing inventory of perishable products. It is clearly suboptimal to incur a disposition charge to remove expired product from store shelves. It is more profitable for the store to adjust the price to stimulate product demand with the goal of ending the cycle with no inventory. We presented preliminary results confirming that consumers will consider purchasing older perishable products if offered a price discount. We also proposed a model simultaneously addressing the importance of dynamically adjusting the product price by taking into account the inventory position and proximity to expiration date in order to maximize store profit for a store.

\section{REFERENCES}

1. Goyal, S., Giri, B., 2001. Recent trends in modeling of deteriorating inventory. European Journal of Operational Research 134 (1), 1-16.

2. Nahmias, S., 1982. Perishable inventory theory: A review Operations Research 30 (3), 680-708.

3. Parlar, M., 1985, Optimal ordering policies for a perishable and substitutable product: A Markov decision model. INFOR, 23 (2), 182-195.

4. Raafat, F., 1991. Survey of literature on continuously deteriorating inventory model. Journal of the Operational Research Society 42, 27-37.

5. Van Donselaar, K. et al. Inventory control of perishables in supermarkets International Journal of Production Economics 104 (2006) 462-472.

6. Young, H. Chun, Optimal pricing and ordering policies for perishable commodities, European Journal of Operational Research 144 (2003) 68-82.

\section{NOTES}

